\title{
Cloning, reassembling and integration of the entire nikkomycin biosynthetic gene cluster into Streptomyces ansochromogenes lead to an improved nikkomycin production
}

\author{
Guojian Liao ${ }^{\dagger}$, Jine $\mathrm{Li}^{\dagger}$, Lei $\mathrm{Li}^{1}$, Haihua Yang ${ }^{1}$, Yuqing $\operatorname{Tian}^{1}$, Huarong $\operatorname{Tan}^{1 *}$
}

\begin{abstract}
Background: Nikkomycins are a group of peptidyl nucleoside antibiotics produced by Streptomyces ansochromogenes. They are competitive inhibitors of chitin synthase and show potent fungicidal, insecticidal, and acaricidal activities. Nikkomycin X and Z are the main components produced by S. ansochromogenes. Generation of a high-producing strain is crucial to scale up nikkomycins production for further clinical trials.

Results: To increase the yields of nikkomycins, an additional copy of nikkomycin biosynthetic gene cluster (35 kb) was introduced into nikkomycin producing strain, S. ansochromogenes 7100 . The gene cluster was first reassembled into an integrative plasmid by Red/ET technology combining with classic cloning methods and then the resulting plasmid(pNIK)was introduced into S. ansochromogenes by conjugal transfer. Introduction of pNIK led to enhanced production of nikkomycins (880 $\mathrm{mg} \mathrm{L}^{-1}, 4$-fold nikkomycin $X$ and $210 \mathrm{mg} \mathrm{L}^{-1}, 1.8$-fold nikkomycin Z) in the resulting exconjugants comparing with the parent strain ( $220 \mathrm{mg} \mathrm{L}^{-1}$ nikkomycin $X$ and $120 \mathrm{mg} \mathrm{L}^{-1}$ nikkomycin Z). The exconjugants are genetically stable in the absence of antibiotic resistance selection pressure.

Conclusion: A high nikkomycins producing strain (1100 $\mathrm{mg} \mathrm{L}^{-1}$ nikkomycins) was obtained by introduction of an extra nikkomycin biosynthetic gene cluster into the genome of $S$. ansochromogenes. The strategies presented here could be applicable to other bacteria to improve the yields of secondary metabolites.
\end{abstract}

\section{Introduction}

Actinomycetes produce a wide variety of secondary metabolites, including antibacterial antibiotics, anticancer agents and immunosuppressive agents. Traditionally, the improvement of antibiotic-producing strain suitable for industrial fermentations is achieved by random mutagenesis and selection techniques. Although these techniques have succeeded in generating many industrial strains, it exhausted time and human resources. Overexpression of positive transcriptional regulators of a biosynthetic cluster or specific enzymes involving in metabolic bottlenecks has significantly overproduced a variety of natural products [1]. Whereas more than a single rate-limiting step often exists in the biosynthetic pathway of secondary

\footnotetext{
* Correspondence: tanhr@sun.im.ac.cn

${ }^{1+}$ State Key Laboratory of Microbial Resources, Institute of Microbiology, Chinese Academy of Sciences, Beijing 100101, PR China
}

metabolites [2], overexpression of the entire antibiotic biosynthetic gene cluster may possibly improve the yields of the desired natural product further.

The positive contribution of amplification of biosynthetic gene clusters to antibiotics production have been previously observed in some industrial overproducing strains [3-5]. For instance, in the kanamycin-overproducing strain, Streptomyces kanamyceticus 12-6 which was generated by classical mutagenesis, tandem amplification of the entire kanamycin $(\mathrm{Km})$ biosynthetic gene cluster was disclosed to directly contribute to $\mathrm{Km}$ overproduction and the level of $\mathrm{Km}$ production depended on the copy number of the $\mathrm{Km}$ biosynthetic gene cluster[5]. This provides a hint that introduction of extra copy of biosynthetic gene cluster into parent strain may be an effective and widespread approach to improve the production of antibiotics. However, the antibiotic biosynthetic gene cluster consisting of structural and
() 
regulatory genes is usually more than $30 \mathrm{~kb}$, which is difficult to identify multiple unique restriction sties and circularize large vectors. So, few reports were related to overexpression of the whole biosynthetic gene cluster in parent strain using directed genetic approaches. Recently, the development of Red/ET technology enabled an alternative means of restriction/ligation-free gene manipulation of the large biosynthetic gene clusters. Red/ET technology is based on the discovery that in engineered $E$. coli containing $\operatorname{Red} \alpha, \operatorname{Red} \beta$, and $\operatorname{Red} \gamma$ proteins from the $\lambda$ phage or RecE/RecT from the Rac phage, allelic exchanges can take place if a given DNA fragment is flanked at both ends by extensions of only a few tens of nucleotides that are homologous to a target DNA region [6,7]. Red/ET technology has become an efficient approach to cloning and modifying whole biosynthetic gene clusters. Biosynthetic gene clusters of myxochromide $S(\sim 30 \mathrm{~kb})$ [8], myxothiazole $(\sim 60 \mathrm{~kb})$ [9], coumermycin A1 ( 38 kb) [10], phenalinolactone $(\sim 42 \mathrm{~kb})$ [11], anthramycin ( 32 kb) [12] and epothilone $(\sim 60 \mathrm{~kb})$ [13] have been successfully constructed by different strategies based on Red/ET technology and heterologously expressed in different strains.

Nikkomycins are a group of peptidyl nucleoside antibiotics with potent fungicidal, insecticidal, and acaricidal activities. They are recognized as ideal fungicide and medications for human being by virtue of its nontoxic to mammals and bees, and easily degradable in nature [14]. Nikkomycin $\mathrm{X}$ and $\mathrm{Z}$ (Fig. 1A), the main components produced by $S$. ansochromogenes, consist of hydoxypyridylhomethreonine (nikkomycin D) and a 5-aminohexuronic acid $\mathrm{N}$-glucosidically bound to uracil in nikkomycin $\mathrm{Z}$ or to 4-formyl-4-imidazolin-2-one (imidazolone) in nikkomycin X. The genes involving in nikkomycin biosynthesis have been identified and the coding regions responsible for the biosynthesis of nikkomycins spanned about $35 \mathrm{~kb}$ on the chromosome of $S$. ansochromogenes and organized in the three transcriptional units $[15,16]$.

In this work, we report application of Red/ET technology combined with classic cloning procedures to construct the whole nikkomycin biosynthetic gene cluster in an integrative plasmid, and investigate the effect of duplication of the entire gene cluster on nikkomycins production in S. ansochromogenes and assess the stability of the engineered nikkomycin producer.

\section{Results}

\section{Reassembling of the nikkomycin biosynthetic gene} cluster by Red/ET

Our previous studies showed that $\operatorname{san} G$ and $\operatorname{san} X$ were indispensable for nikkomycin biosynthesis and their disruption led to the abolishment of nikkomycin production $[17,18]$, whereas deletion of a $8 \mathrm{~kb}$ upstream of $\operatorname{san} G$ or $3 \mathrm{~kb}$ downstream of $\operatorname{san} X$ did not affect

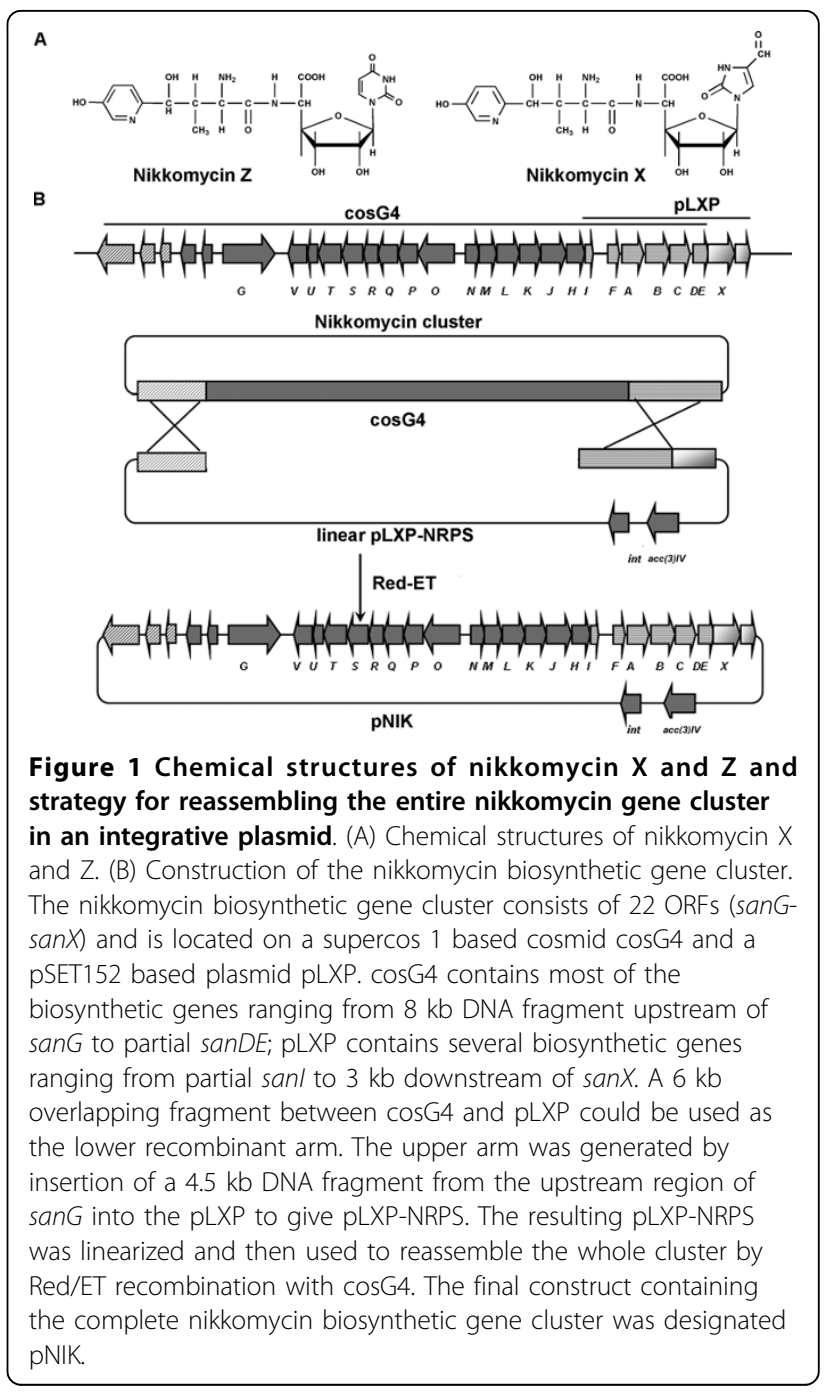

nikkomycin production (data not shown). These results suggest that $\operatorname{san} G$ is at the left boundary of the nikkomycin cluster and $\operatorname{san} X$ is at the right boundary. To obtain the nikkomycin biosynthetic gene cluster, a cosmid library of genomic DNA from S. ansocrhomogenes 7100 was constructed and screened by PCR. A cosmid named cosG4 containing most of the genes involving in nikkomycin biosynthesis was obtained. It harbored DNA sequences ranging from $8 \mathrm{~kb}$ upstream of $\operatorname{san} G$ to $\operatorname{san} C$ and partial sanDE, whereas intact sanDE and sanX, which were also essential for nikkomycin biosynthesis, were not located on cosG4 (Fig. 1B). pLXP, a plasmid based on PSET152, had an $11 \mathrm{~kb}$ insertional sequence containing the partial sanI and complete $\operatorname{san} F$, sanA, $\operatorname{san} B, \operatorname{san} C, \operatorname{san} D E$, $\operatorname{san} X$ and $3 \mathrm{~kb}$ downstream of $\operatorname{san} X$ [18]. cosG4 and pLXP harbored $6 \mathrm{~kb}$ overlapping regions, which enabled the use of Red/ET recombination to reassemble both parts to construct the nikkomycin biosynthetic gene cluster (NIK gene cluster). 
Reconstruction of the NIK gene cluster in a single plasmid was performed as described in the section of Materials and Methods(Fig. 1B)and the final construct was designated as pNIK. The identity of pNIK was further confirmed through PCR and restrictive analysis (Fig. 2).

\section{Duplication of the NIK gene cluster in $S$.}

\section{ansochromogenes 7100}

pNIK was passed through E. coli ET12567/pUZ8002 and then introduced into $S$. ansochromogenes 7100 by conjugal transfer according to established techniques. The resulting transformants were inoculated on MS plates in the presence of apramycin to form spores. Gray spores were harvested and transferred into liquid medium.

Three apramycin-resistant transformants were obtained and all of them led to an improved nikkomycin production ranging from 4-fold to 5-fold (Fig. 3). As control, introduction of pSET152 into the chromosome of S. ansochromogenes had no effect on nikkomycin production (data not shown). One of the tranformants, designated DNik, was chosen for further investigation. To verify the integration of pNIK into the genome of $S$. ansochromogenes, genomic DNA of S. ansochromogenes 7100, S. ansochromogenes 7100 (pSET152) and DNik was isolated and used as template to perform PCR. A 964 bp of DNA fragment was amplified from genomic DNA of $S$. ansochromogenes 7100 (pSET152) and DNik, but not from S. ansochromogenes

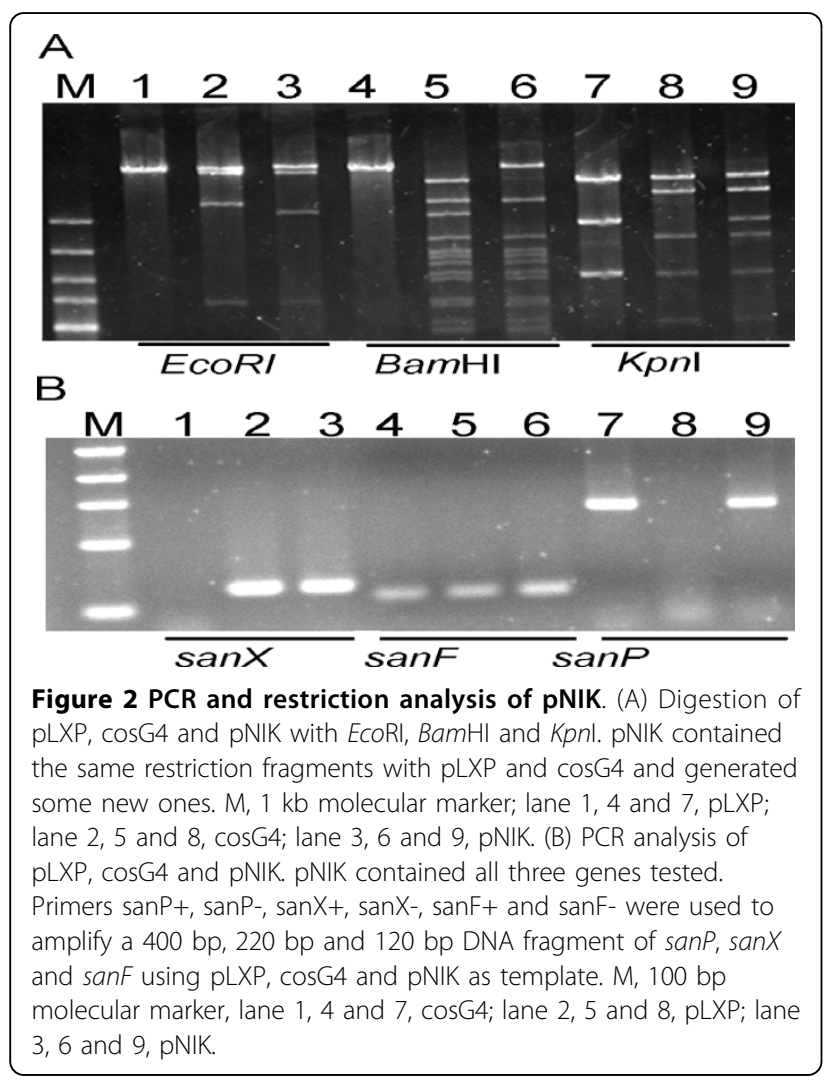

7100 (Fig. 4), demonstrating that pNIK integrated at the $a t t B$ site in the genome of $S$. ansochromogenes. The $S$. ansochromogenes 7100 (pSET152) and DNik had comparable growth rates and final biomass (Fig. 5A), indicating that higher biomass was not an overproduction mechanism of DNik. DNik showed higher nikkomycins production than S. ansochromogenes 7100 (pSET152) after incubation for 2 days, and 4.3-fold (1100 mg/L) much higher production after 5 days (Fig. 5B). Furthermore, introduction of pNIK into S. ansochromogenes 7100 had different effect on the yields of nikkomycin $\mathrm{X}$ and nikkomycin Z, leading to 4-fold ( $880 \mathrm{mg} / \mathrm{L}$ ) improvement of nikkomycin $X$ production and 1.8 -fold $(220 \mathrm{mg} / \mathrm{L})$ of nikkomycin Z (Fig. 5C and 5D).

To investigate the stability of DNik, the mutant was incubated in the absence of apramycin. After 5 passages, 10 colonies were randomly selected and cultured in the presence of apramycin for 5 days. All of them still conferred apramycin resistance and produced approximately 4.2-fold of yields of nikkomycins compared with the parent strain (data not shown). These results demonstrated that the transformants harboring one extra copy of NIK gene cluster are genetically stable in $S$. ansochromogenes.

\section{Discussion}

Duplication of biosynthetic gene clusters to increase the yields of secondary metabolites had been applied using directed genetic approaches. In fungi, introduction of the whole biosynthetic gene cluster of penicillin into penicillin producing strain Penicillium chysogenum Wis54-1255 and that of compactin into P. citrinum resulted in significantly increased production of

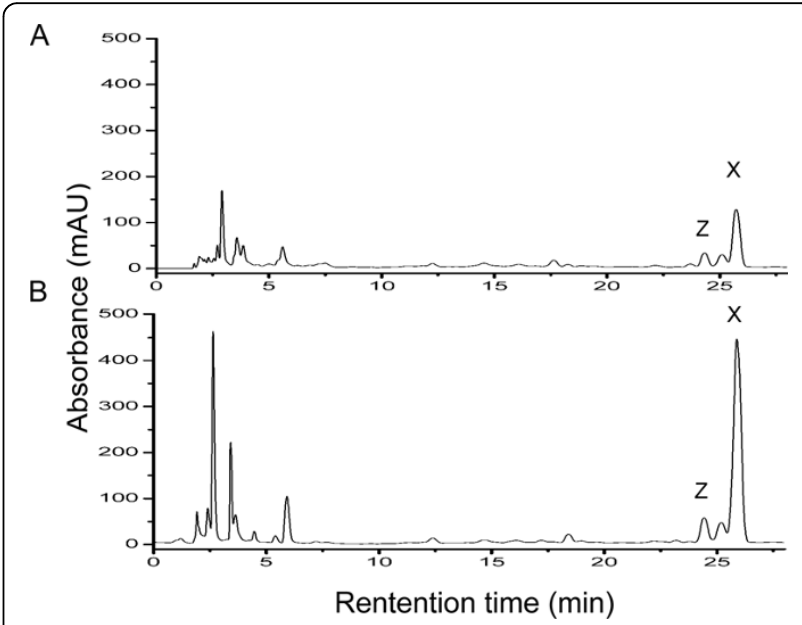

Figure 3 HPLC analysis of Nikkomycins production in $S$. ansochromogenes and its derivatives. (A) S. ansochromogenes 7100 (pSET152); (B) DNik. The strains were inoculated in liquid SP medium for 120 h. X, nikkomycin X; Z, nikkomycin Z. 


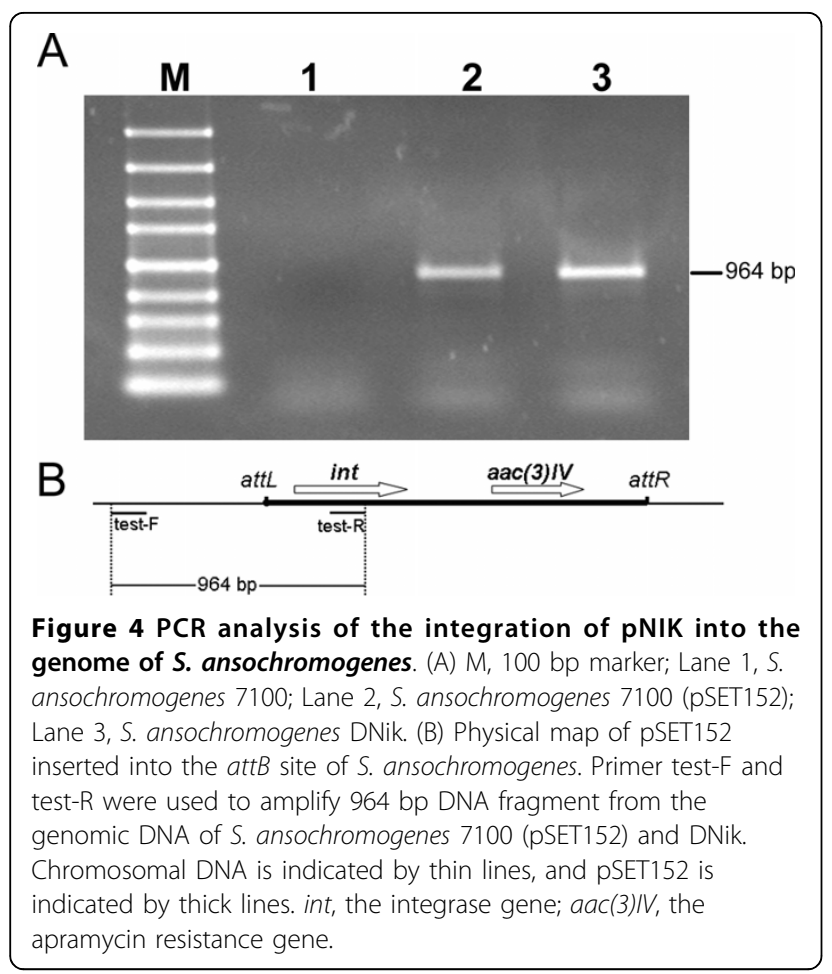

penicillin and compactin, respectively $[19,20]$. In Streptomyces, when the whole gene cluster of cephamycin $\mathrm{C}$ from $S$. cattleya was introduced into another cephamycin producer, S. lactamgens, a 2 to 3 -fold improvement in titer was achieved [21]. However, in these cases, cosmids were applied to load the antibiotic gene clusters. Isolation of an intact biosynthetic gene cluster onto a single comsid was extremely difficult owing to its large size. Instead, construction of the whole biosynthetic gene cluster from several cosmids or plasmids which contained partial DNA fragments of the cluster was more feasible and the development of Red/ET technology facilitated this procedure. In this work, we employed Red/ET technology to reassemble the entire NIK cluster in an integrative vector, pSET152, which potentially allowed the resulting nikkomycin overproducer with genetic stability and demonstrated positive effect of introduction of NIK cluster into the parent strain on nikkomycins production. Our results were consistent with other groups' similar results, showing that duplication of NIK cluster could significantly improve the yields of nikkomycins.

It is common that high-producing strains containing a self-replicating plasmid or cosmid usually lose their high
A
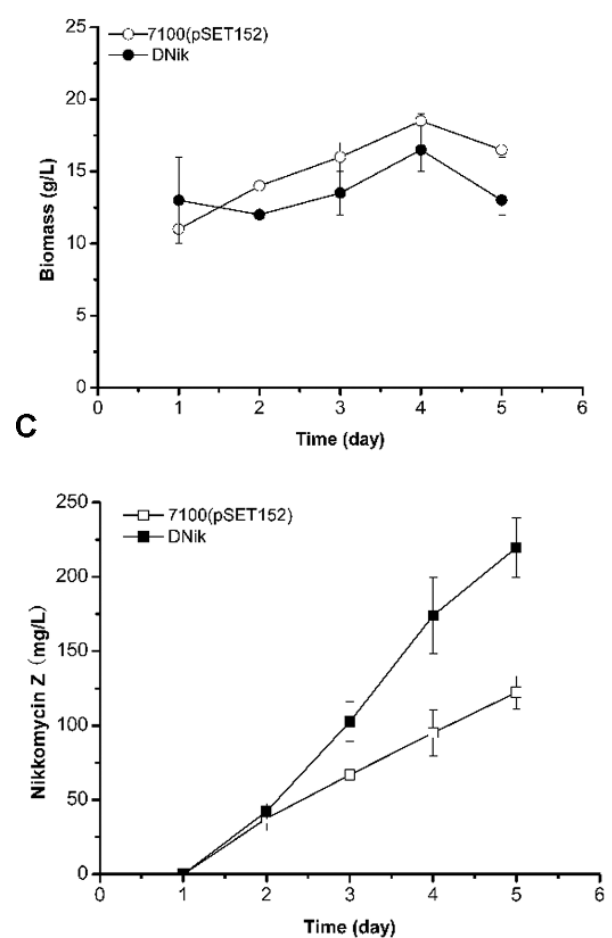

B
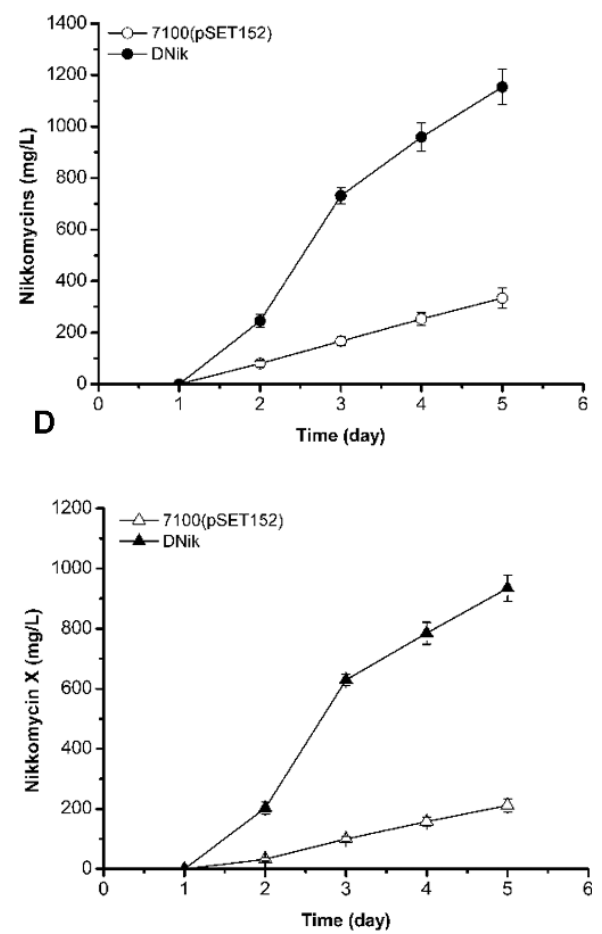

Figure 5 Nikkomycins production and biomass of S. ansochromogenes and its derivatives in SP medium. (A) Biomass. S. ansochromogenes 7100 (pSET152) (open circle), DNik (close circle); (B) Total nikkomycins production; (C) Nikkomycin Z production. S. ansochromogenes 7100(pSET152) (open square), DNik (close square); (D) Nikkomycin X production. S. ansochromogenes 7100(pSET152) (open triangle), DNik (close triangle). 
producing ability when they are incubated in the absence of antibiotic resistance selection pressure [21]. However, it was impractical to culture strains in large scale in the presence of antibiotics. pSET152, which could be introduced into Streptomyces by conjugal transfer and stably integrated into the Streptomyces chromosome by sitespecific recombination at the phage $\phi \mathrm{C} 31$ attachment site (attB) [22], provided an alternative to get stable highproducing strains. It was feasible to construct the whole secondary biosynthetic gene cluster using Red/ET technology into PSET152 or other vectors which contained the DNA fragments of oriT (RK2) region, the phage $\phi$ C31 attachment site and integrase gene from pSET152. As a linear relationship was observed between the cluster copy number and the yields of antibiotics $[3,5]$, more copies of the gene cluster could be introduced into the Streptomyces chromosome using other phage based plasmids (e.g. pSAM2, pSOK804 or pRT801), which integrated at sites different from the $\phi \mathrm{C} 31$ [23]. Recently, Tyo and colleagues developed an efficient approach to increase the copy number of target DNA fragment in $E$. coli using chemically inducible chromosomal evolution (CICHE) [24] and its application in Streptomyces would facilitate the introduction of more copy of whole biosynthetic gene cluster into the Streptomyces chromosome. It is noteworthy that the highest nikkomycin production reported is $3.2 \mathrm{~g} / \mathrm{L}$ in S. tandae Tü 901/S 2556, which was subjected to multiple rounds of strain improvement [25]. Therefore, we expect that introduction of extra copy of NIK cluster could be a potential strategy for further increase of nikkomycin production.

Duplication of the whole NIK cluster had different effect on the nikkomycin $\mathrm{X}$ and nikkomycin $\mathrm{Z}$ production. Nikkomycin $\mathrm{X}$ and $\mathrm{Z}$ had the same peptidyl moiety but different nucleoside moiety. Imidazolone, the base of nikkomycin $X$, was catalyzed by enzymes encoded by sanO, san $Q$ and sanP from $S$. ansochromogenes [26], whereas uracil, the base of nikkomycin $Z$, was synthesized by de novo synthesis or salvage pathway. Duplication of the NIK gene cluster may increase the transcription of the whole transcriptional units, providing more precursors for biosynthesis of nikkomycin X. However, duplication of the NIK gene cluster could not significantly increase the pool of uracil, resulting in a modest increase in nikkomycin $\mathrm{Z}$ production (1.8-fold). These results were consistent with our previous results that overexpression of $\operatorname{sanO}$ could only increase the yields of nikkomycin X [27].

\section{Conclusion}

Development of new techniques and tools for gene manipulation (e.g. Red/ET recombination) significantly facilitate cloning and reassembling of antibiotic gene clusters with large size in a given vector. In this study, Red/ET approach was applied to reassemble the entire nikkomycin biosynthetic gene cluster in an integrative vector, allowing the generation of a stable nikkomycin overproducer. Our investigation provides an insight that introduction of the biosynthetic gene cluster into parent strain could be a simple and widespread approach for improving the yields of antibiotics of commercial interest.

\section{Materials and methods}

\section{Bacterial strains, plasmids and growth conditions}

Bacterial strains and plasmids used in this study are listed in Table 1. S. ansochromogenes 7100, the wild type producer of nikkomycin $(120 \mathrm{mg} / \mathrm{L}$ nikkomycin $\mathrm{Z}$ and $220 \mathrm{mg} / \mathrm{L}$ nikkomycin X), was collected in our laboratory. S. ansochromogenes and its derivative strains were grown at $28^{\circ} \mathrm{C}$ in different media. Liquid medium YEME and solid medium MS were prepared as described elsewhere[28]. SP medium (3\% mannitol, $1 \%$ soluble starch, $0.5 \%$ soy peptone and $0.8 \%$ yeast extract, $\mathrm{pH} 6.0$ ) was used for nikkomycins production. $E$. coli strains were incubated in $\mathrm{LB}$ medium at $37^{\circ} \mathrm{C}$ or $30^{\circ} \mathrm{C}$ (for Red/ET protein expression). When necessary, antibiotics were used at the following concentrations: apramycin, $10 \mu \mathrm{g}$ $\mathrm{ml}^{-1}$ in YEME or MS for S. ansochromogenes, $100 \mu \mathrm{g}$ $\mathrm{ml}^{-1}$ in LB for E. coli; kanamycin, $10 \mu \mathrm{g} \mathrm{ml}^{-1}$ in YEME or MS for $S$. ansochromogenes, $100 \mu \mathrm{g} \mathrm{ml}^{-1}$ in LB for E. coli and choramphenicol $34 \mu \mathrm{g} \mathrm{ml}^{-1}$ in LB for E. coli.

\section{Primers and Polymerase chain reactions}

Polymerase chain reactions (PCRs) were performed using Taq DNA polymerase. sanP+: GCGGCCAGCTACTTCCGGGAC, sanP-: GCAGAAAGGCCGAGCGCATGT; sanX+: GCAGAAAGGCCGAGCGCATGT, sanX-: GCTACAGCGGGGCGGTCAAG; sanF+: CAGG TCGGGGATCAGGGTC, sanF-: GCGGCCAGCTAC TTCCGGGAC; all of them were used to confirm the identity of pNIK. An initial denaturation at $95^{\circ} \mathrm{C}$ for 5 min was followed by 30 cycles of amplification $\left(95^{\circ} \mathrm{C}\right.$ for $1 \mathrm{~min}, 60^{\circ} \mathrm{C}$ for $30 \mathrm{~s}$ and $72^{\circ} \mathrm{C}$ for $1 \mathrm{~min}$ ) and additional $10 \mathrm{~min}$ at $72^{\circ} \mathrm{C}$.

\section{Construction of genomic library for S. ansochromogenes}

For construction of a cosmid library of S. ansocrhomogenes, $10 \mu \mathrm{g}$ of chromosomal DNA was partially digested with Sau3AI. The 30-45 kb DNA fragments were isolated and ligated into supercos 1 . After incubation at $16^{\circ} \mathrm{C}$ for $16 \mathrm{~h}$, the ligated DNA was packaged using Gigapack III XL packaging kit (Stratagene) and introduced into E. coli XL-blue MR. The cosmid library was screened by PCR using primers sanP+ 5' GCGGCC AGCTACTTCCGGGAC 3' and sanP- 5' GCAGAAAGG CCGAGCGCATGT 3'. Cosmid (mix) was used as template and the positive clones were identified in 96-well plates.

Reassembling of the entire nikkomycin biosynthetic gene cluster by Red/ET

The Red/ET recombination technique was described previously [6]. In the present study this method was 
Table 1 Strains and plasmids used in this study.

\begin{tabular}{|c|c|c|}
\hline Strains or plasmids & Relevant characteristics & Sources \\
\hline \multicolumn{3}{|l|}{ Bacterial strains } \\
\hline \multicolumn{3}{|l|}{ S. ansochromogenes } \\
\hline 7100 & Wild-type strain & {$[31]$} \\
\hline DNik & S. ansochromogenes 7100 containing plasmid pNIK & This work \\
\hline \multicolumn{3}{|l|}{ E. coli } \\
\hline $\mathrm{DH} 5 \alpha$ & F-recA, f80, d/acZ $\Delta \mathrm{M} 15$ & Gibco BRL \\
\hline ET12567 (pUZ8002) & recE, dam, dcm, hsdS, Cm, Str, Tet, Km & {$[32]$} \\
\hline XL 1-blue MR & $\Delta(m c r A) 183, \Delta(m c r C B-h s d S M R-m r r) 173$, endA1, supE44, thi-1, recA1, gyrA96, relA1, lac & Stratagene \\
\hline BW25113 & K12 derivative: $\triangle a r a B A D, \triangle r h a B A D$ & [33] \\
\hline \multicolumn{3}{|l|}{ Plasmids } \\
\hline pBluescript KS- & Routine cloning and subcloning vector & Stratagene \\
\hline $\mathrm{pBS}$ & Digestion of pBluescript II KS- with BamHI-Pstl, blunt-ended and religation. & This work \\
\hline supercos 1 & Vector for cosmid library construction & Stratagene \\
\hline pSET152 & Integrative vector & {$[22]$} \\
\hline plJ790 & $\lambda \operatorname{RED}\left(\mathrm{gam}\right.$, bet, exo), cat, araC, rep $101^{\text {ts }}$ & [33] \\
\hline $\cos G 4$ & A cosmid containing most of the nikkomycin biosynthetic genes & This work \\
\hline $\mathrm{pLXP}$ & 11 kb DNA fragment containing partial nikkomycin biosynthetic genes inserted into pSET152 & [18] \\
\hline pNIK & A pSET152 based plasmid containing the whole nikkomycin biosynthetic gene cluster & This work \\
\hline
\end{tabular}

used for reassembling the whole nikkomycin biosynthetic gene cluster onto an integrative plasmid.

A $4.5 \mathrm{~kb} E c o R I-X h o I$ DNA fragment containing the upstream region of $\operatorname{san} G$ from cosG4 was inserted into the same site of pBS-1 to generate pNRPS, and then digested with $\mathrm{XbaI} / \mathrm{Bam} \mathrm{HI}$. The resulting $4.5 \mathrm{~kb}$ DNA fragment was inserted into the same site of pLXP to give pLXP-NRPS. Subsequently, pLXP-NRPS was digested with $B a m \mathrm{HI}$, dephosphorated with calf phosphatase (Takara, Japan) to generate the two recombinant arms for Red/ET recombination. The resulting linear fragment $(1 \mu \mathrm{g})$ was then introduced into $E$. coli BW25113/pIJ790 containing cosmid cosG4 by electroporation. The pNIK was selected by apramycin resistance.

\section{Integration of pNIK into the genome of $S$. ansochromogenes}

phiC31 integrase in pSET152 can integrate intragenically into the $a t t B$ site of SCO3798 of S. coelicolor [29]. SCO3798 is a highly conserved gene in Streptomyces and its homologue (92\% identity) is found in genome of $S$. ansochromogenes after whole genome 454 sequencing (Li, et al, unpublished results). Primer test-F: GGTGT CGCCGTTGGTGATG and test-R: GGCTTGAAGGGA AGGTGTTTGT were used to verify the integration of pSET152 or pNIK into the genome of $S$. ansochromogenes.

\section{HPLC analysis of nikkomycins}

Spores of $S$. anchromogenes were inoculated in YEME. The cultures were grown at $28^{\circ} \mathrm{C}$ on a rotary shaker $(220 \mathrm{rpm})$ for $48 \mathrm{~h}$ and used as seed cultures. $1 \mathrm{ml}$ $(0.5 \% \mathrm{~V} / \mathrm{V})$ of seed culture was inoculated into flasks containing $50 \mathrm{ml}$ of SP medium, and then fermented at $28^{\circ} \mathrm{C}$ on a rotary shaker $(200 \mathrm{rpm})$ for 5 days. The culture filtrates were harvested by centrifugation and the supernatant was filtered through a Minipore membrane (pore diameter $0.2 \mu \mathrm{m}$ ). Nikkomycins were identified by HPLC analysis (Agilent 1100 HPLC and RPC-18) at 290 $\mathrm{nm}$ absorption wavelengths. Chemical reagent, mobile phase and gradient elution process were as described by Fiedler [30].

\section{Acknowledgements}

This work was supported by grants from the Chinese Academy of Sciences (Grant no. KSCX2-YW-N-027) and from the Ministry of Science and

Technology of China (Grant nos. 2009CB118905 and 2006AA10A209).

\section{Author details}

${ }^{1+}$ State Key Laboratory of Microbial Resources, Institute of Microbiology, Chinese Academy of Sciences, Beijing 100101, PR China. ${ }^{2}$ Graduate School of Chinese Academy of Sciences, Beijing 100039, PR China.

\section{Authors' contributions}

$G L$ and $J$ carried out the experiments and analyzed the primary data. $G L$ wrote the draft manuscript. $L L, H Y$ and $Y T$ assisted with experimental design and data analysis. HT supervised the whole work and revised the manuscript. All authors read and approved the final manuscript.

\section{Competing interests}

The authors declare that they have no competing interests.

Received: 14 November 2009

Accepted: 23 January 2010 Published: 23 January 2010

\section{References}

1. Olano C, Lombo F, Mendez C, Salas JA: Improving production of bioactive secondary metabolites in actinomycetes by metabolic engineering. Metab Eng 2008, 10(5):281-292.

2. Santos CN, Stephanopoulos G: Combinatorial engineering of microbes for optimizing cellular phenotype. Curr Opin Chem Biol 2008, 12(2):168-176. 
3. Fierro F, Barredo JL, Diez B, Gutierrez S, Fernandez FJ, Martin JF: The penicillin gene cluster is amplified in tandem repeats linked by conserved hexanucleotide sequences. Proc Natl Acad Sci USA 1995, 92(13):6200-6204.

4. Peschke U, Schmidt H, Zhang HZ, Piepersberg W: Molecular characterization of the lincomycin-production gene cluster of Streptomyces lincolnensis 78-11. Mol Microbiol 1995, 16(6):1137-1156.

5. Yanai K, Murakami T, Bibb M: Amplification of the entire kanamycin biosynthetic gene cluster during empirical strain improvement of Streptomyces kanamyceticus. Proc Natl Acad Sci USA 2006, 103(25):96619666.

6. Zhang Y, Buchholz F, Muyrers JP, Stewart AF: A new logic for DNA engineering using recombination in Escherichia coli. Nat Genet 1998, 20(2):123-128.

7. Zhang Y, Muyrers JP, Testa G, Stewart AF: DNA cloning by homologous recombination in Escherichia coli. Nat Biotechnol 2000, 18(12):1314-1317.

8. Wenzel SC, Gross F, Zhang Y, Fu J, Stewart AF, Muller R: Heterologous expression of a myxobacterial natural products assembly line in pseudomonads via red/ET recombineering. Chem Biol 2005, 12(3):349-356.

9. Perlova O, Fu J, Kuhlmann S, Krug D, Stewart AF, Zhang Y, Muller R: Reconstitution of the myxothiazol biosynthetic gene cluster by Red/ET recombination and heterologous expression in Myxococcus xanthus. Appl Environ Microbiol 2006, 72(12):7485-7494.

10. Wolpert M, Heide L, Kammerer B, Gust B: Assembly and heterologous expression of the coumermycin A1 gene cluster and production of new derivatives by genetic engineering. Chembiochem 2008, 9(4):603-612

11. Binz TM, Wenzel SC, Schnell HJ, Bechthold A, Muller R: Heterologous expression and genetic engineering of the phenalinolactone biosynthetic gene cluster by using red/ET recombineering. Chembiochem 2008, 9(3):447-454

12. Hu Y, Phelan W, Farnet CM, Zazopoulos E, Bachmann BO: Reassembly of anthramycin biosynthetic gene cluster by using recombinogenic cassettes. Chembiochem 2008, 9(10):1603-1608.

13. Fu J, Wenzel SC, Perlova O, Wang J, Gross F, Tang Z, Yin Y, Stewart AF, Muller $R$, Zhang $Y$ : Efficient transfer of two large secondary metabolite pathway gene clusters into heterologous hosts by transposition. Nucleic Acids Res 2008, 36(17):e113.

14. Hector RF: Compounds active against cell walls of medically important fungi. Clin Microbiol Rev 1993, 6(1):1-21.

15. Lauer B, Russwurm R, Schwarz W, Kalmanczhelyi A, Bruntner C, Rosemeier A, Bormann C: Molecular characterization of co-transcribed genes from Streptomyces tendae Tu901 involved in the biosynthesis of the peptidyl moiety and assembly of the peptidyl nucleoside antibiotic nikkomycin. Mol Gen Genet 2001, 264(5):662-673.

16. Bruntner C, Lauer B, Schwarz W, Mohrle V, Bormann C: Molecular characterization of co-transcribed genes from Streptomyces tendae Tu901 involved in the biosynthesis of the peptidyl moiety of the peptidyl nucleoside antibiotic nikkomycin. Mol Gen Genet 1999, 262(1):102-114.

17. Liu G, Tian $Y$, Yang $H$, Tan $H$ : A pathway-specific transcriptional regulatory gene for nikkomycin biosynthesis in Streptomyces ansochromogenes that also influences colony development. Mol Microbiol 2005, 55(6):1855-1866.

18. Li W: Structure and Function of Gene Involved in Nikkomycin Biosynthesis and Differentiation in Streptomyces ansochromogenes. PhD Dissertation. Beijing: Institute of microbiology, CAS 2003.

19. Theilgaard H, Berg van Den M, Mulder C, Bovenberg R, Nielsen J: Quantitative analysis of Penicillium chrysogenum Wis54-1255 transformants overexpressing the penicillin biosynthetic genes. Biotechnol Bioeng 2001, 72(4):379-388.

20. Baba S, Abe Y, Suzuki T, Ono C, Iwamoto K, Nihira T, Hosobuchi M: Improvement of compactin (ML-236B) production by genetic engineering in compactin high-producing Penicillium citrinum. Appl Microbiol Biotechnol 2009, 83(4):697-704

21. Chen CW, Lin H-F, Kuo CL, Tsai H-L, Tsai JF-Y: Cloning and Expression of a DNA Sequence Conferring Cephamycin C Production. Bio/Technology 1988, 6:1222-1224.

22. Bierman M, Logan $R$, O'Brien $K$, Seno ET, Rao RN, Schoner BE: Plasmid cloning vectors for the conjugal transfer of DNA from Escherichia coli to Streptomyces spp. Gene 1992, 116(1):43-49.
23. Ostash B, Makitrinskyy R, Walker S, Fedorenko V: Identification and characterization of Streptomyces ghanaensis ATCC14672 integration sites for three actinophage-based plasmids. Plasmid 2009, 61(3):171-175.

24. Tyo KE, Ajikumar PK, Stephanopoulos G: Stabilized gene duplication enables long-term selection-free heterologous pathway expression. Nat Biotechnol 2009, 27(8):760-765.

25. Fiedler H-P, Schuz T, Decker H: An overview of nikkomycins: history, biochemistry and applications. Cutaneous antifungal agents:selected compounds in clinical practice and development New York: Marcel Dekker, IncRippon JW, Fromtling RA 1993, 325-352.

26. Chen H, Hubbard BK, O'Connor SE, Walsh CT: Formation of beta-hydroxy histidine in the biosynthesis of nikkomycin antibiotics. Chem Biol 2002, 9(1):103-112

27. Wang G, Tan H: Enhanced production of nikkomycin X by overexpression of SanO, a non-ribosomal peptide synthetase in Streptomyces ansochromogenes. Biotechnol Lett 2004, 26(3):229-233.

28. Kieser T, Bibb MJ, Buttner MJ, Chater KF, Hopwood DA: Practical Streptomyces Genetics. the John Innes Foundation, Norwich, England 2000

29. Combes $P$, Till $R$, Bee $S$, Smith MC: The streptomyces genome contains multiple pseudo-attB sites for the (phi)C31-encoded site-specific recombination system. J Bacteriol 2002, 184(20):5746-5752.

30. Fiedler HP: Screening for new microbial products by high-performance liquid chromatography using a photodiode array detector. I Chromatogr 1984, 316:487-494

31. Zeng $\mathrm{H}$, Tan $\mathrm{H}$, Li J: Cloning and function of sanQ: a gene involved in nikkomycin biosynthesis of Streptomyces ansochromogenes. Curr Microbiol 2002, 45(3):175-179.

32. Paget MS, Leibovitz E, Buttner MJ: A putative two-component signal transduction system regulates sigmaE, a sigma factor required for normal cell wall integrity in Streptomyces coelicolor A3(2). Mol Microbiol 1999, 33(1):97-107.

33. Gust B, Challis GL, Fowler K, Kieser T, Chater KF: PCR-targeted Streptomyces gene replacement identifies a protein domain needed for biosynthesis of the sesquiterpene soil odor geosmin. Proc Natl Acad Sci USA 2003, 100(4):1541-1546.

doi:10.1186/1475-2859-9-6

Cite this article as: Liao et al: Cloning, reassembling and integration of the entire nikkomycin biosynthetic gene cluster into Streptomyces ansochromogenes lead to an improved nikkomycin production. Microbial Cell Factories 2010 9:6.

\section{Submit your next manuscript to BioMed Central and take full advantage of:}

- Convenient online submission

- Thorough peer review

- No space constraints or color figure charges

- Immediate publication on acceptance

- Inclusion in PubMed, CAS, Scopus and Google Scholar

- Research which is freely available for redistribution 